\title{
NANOCRYSTAL, PHASE TRANSFORMATION AND MICROSTRUCTURE OF NI50 TI50 SHAPE MEMORY ALLOY
}

\author{
M.Dovchinvanchig ${ }^{1 *}$, Chunwang Zhao ${ }^{2}$ \\ ${ }^{1}$ School of Engineering and Technology, Mongolian University of Life Sciences, \\ Ulaanbaatar, Mongolia \\ ${ }^{2}$ College of Arts and Sciences, Shanghai Maritime University, 201306 Shanghai, China \\ *Corresponding author: Dovchinvanchig@muls.edu.mn
}

\begin{abstract}
:
The nanocrystal, phase transformation and microstructure behavior of NisoTi $i_{50}$ shape memory alloy was investigated by scanning electronic microscope, X-ray diffraction and differential scanning calorimetry. The results showed that the microstructure of Ni-Ti binary alloy consists of the NiTi $i_{2}$ phase and the NiTi matrix phase. One-step phase transformation was observed alloy.
\end{abstract}

KEYWORDS: Shape memory effect; Super-elasticity, Martensitic transformation;

\section{INTRODUCTION}

Ni-Ti based shape memory alloys (SMAs) is a very important material because it owns unique shape memory effect and super-elasticity behaviors [1]. Today this kind of material has been used in many different fields, especially in engineering and medical application. Current research interest on SMA are mainly controlling the martensitic transformation temperature and improving the shape memory effect for their applications. The effect of martensitic transformation, super-elasticity and shape memory effect have been studied widely by adding transitional elements to Ni-Ti binary alloys which has included

\section{MATERIALS AND METHODS}

The $\mathrm{Ni}_{50} \mathrm{Ti}_{50}$ alloy were prepared by melting each $10 \mathrm{~g}$ of raw materials with different nominal compositions (99.9 mass\% sponge Ti, 99.7 mass\% electrolytic Ni) in a nonconsumable arc-melting furnace using a water-cooled copper crucible. The alloy in denoted $\mathrm{Ni}_{50} \mathrm{Ti}_{50}$ alloy, respectively. Are-melting was repeated four times to ensure the uniformity of composition. The specimens are spark-cut from the ingots and solution -treated at $850^{\circ} \mathrm{C}$ for an hour in a quartz tube furnace. Subsequently the specimens were quenched using water. Thereafter, the specimens are
$\mathrm{Fe}, \mathrm{Nb}, \mathrm{Hf}, \mathrm{Zr}, \mathrm{Pd}, \mathrm{Pt}$, etc. Among, $\mathrm{Fe}$ and $\mathrm{Nb}$ have been added to Ni-Ti binary alloys, which decreased the martensitic transformation temperature. But, Hf, $\mathrm{Zr}$, $\mathrm{Pd}$ and $\mathrm{Pt}$ addition can increase the martensitic transformation temperature of $\mathrm{Ni}-\mathrm{Ti}$ alloys. Moreover, the nanocrystal, microstructure and martensitic transformation temperature of the Ni-Ti binary alloys have also been studied using scanning electron microscopy (SEM), energy dispersive spectrometry (EDS), X-ray diffraction (XRD), and differential scanning calorimetry (DSC).

mechanically and lightly polished to obtain a plain surface.The phase transformation temperature of $\mathrm{Ni}_{50} \mathrm{Ti}_{50}$ alloy were determined by DSC using a TA Q2000 calorimeter. The temperature range of heating and cooling was from $-30^{\circ} \mathrm{C}$ to $155^{\circ} \mathrm{C}$, and the scanning rate of heating and cooling was $10^{\circ} \mathrm{C} / \mathrm{min}$. SEM observations were conducted using a FEI Quanta 650 FEG equipped with EDS analysis systems made by Oxford. An XRD experiment was conducted using a D/MAX-2500PC X-ray diffractometer. 


\section{RESULTS AND DISCUSSION}

\section{Microstructure of $\mathrm{Ni}_{50} \mathbf{T i}_{50}$ alloy}

Fig.1 depicts the back-scattering SEM images of $\mathrm{Ni}_{50} \mathrm{Ti}_{50}$ alloy. There are two different morphologies, namely, black phase and matrix can be identified in the SEM image. The black phase is in irregular shape and distributed randomly in the matrix. To analyze the chemical composition Ni-Ti alloy, EDS measurement was conducted during SEM and the results are shown in Table.1. The Ti:Ni ratio in the matrix of all Ni-Ti alloy is measured to be near 1 . Thus, the matrix can concluded to be NiTi phase. The Ti:Ni ratio in the black phase of $\mathrm{Ni}-\mathrm{Ti}$ alloy is measured to be near 2:1. By XRD analysis, there is a $\mathrm{NiTi}_{2}$ phase in $\mathrm{Ni}_{50} \mathrm{Ti}_{50}$. Thus, the black phase can be concluded to be $\mathrm{NiTi}_{2}$.

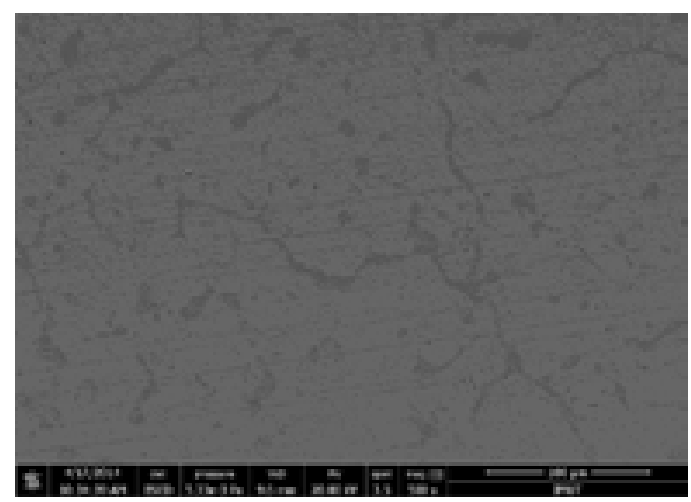

Figure 1. Back-scattering SEM image $\mathrm{Ni}_{50} \mathrm{Ti}_{50}$

Table 1.

Composition of Ni-Ti alloy

\begin{tabular}{cccc}
\hline Alloy & Phase & Ti (at. \%) & Ni (at. \%) \\
\hline \multirow{2}{*}{$\mathrm{Ni}_{50} \mathrm{Ti}_{50}$} & $\begin{array}{c}\text { matrix } \\
\text { black } \\
\text { phase }\end{array}$ & 50.64 & 49.36 \\
& 66.99 & 33.01 \\
\hline
\end{tabular}

\section{XRD analysis of $\mathrm{Ni}_{50} \mathrm{Ti}_{50}$ alloy}

Fig. 2 depicts the XRD curve of $\mathrm{Ni}_{50} \mathrm{Ti}_{50}$ alloy at room temperature. The diffraction peaks are identified to be from NiTi B19' martensite phase and $\mathrm{NiTi}_{2}$ phase alloy after comparing with JCPDF cards (numbers 65-0145 and 72-0442). The detailed crystal plane indices are marked in Fig. 1 for the relative intensities of each XRD curve are quite different because of the differences in martensite phase fraction and $\mathrm{NiTi}_{2}$ phase fraction. In this paper, the letter denotes the
NiTi B19' martensite phase and the denotes the $\mathrm{NiTi}_{2}$ phase. This perspective will be confirmed in the following DSC analysis. The lattice parameters of alloy can be also calculated by peaks position in XRD curve and shows in Table.2 It is shown clearly that cell volume V expand for either Ni-Ti binary alloy. The observation can also be confirmed in the following composition analysis.

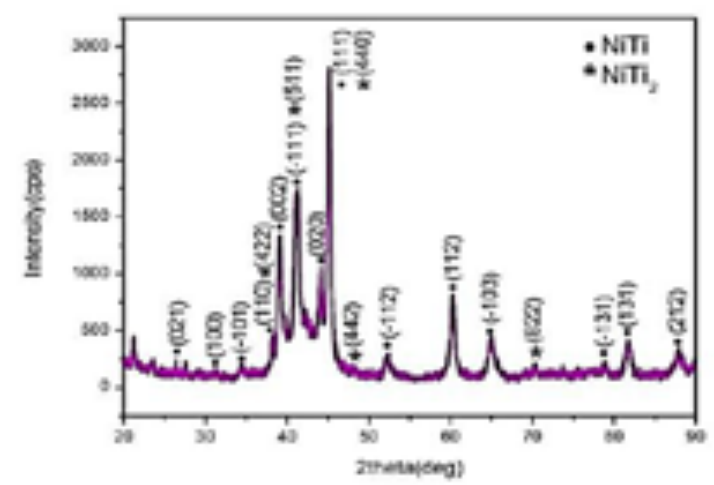

Figure 2. XRD curve of $\mathrm{Ni}_{50} \mathrm{Ti}_{5}$ 
Table 2.

Lattice parameters of Ni-Ti alloy

\begin{tabular}{cccccccc}
\hline Alloy & Phase & $a(\mathrm{~nm})$ & $b(\mathrm{~nm})$ & $c(\mathrm{~nm})$ & $\beta\left(^{\circ}\right)$ & $V\left(\mathrm{~nm}^{3}\right)$ & Source \\
\hline $\mathrm{Ni}_{50} \mathrm{Ti}_{50}$ & $\mathrm{M}$ & 0.2898 & 0.4121 & 0.4619 & 97.86 & 0.05465 & $\begin{array}{c}\text { This work } \\
\mathrm{NiTi}\end{array}$ \\
$\mathrm{M}$ & 0.2898 & 0.4108 & 0.4646 & 97.78 & 0.05480 & $\begin{array}{c}\text { JCPDF card } \\
\text { No.65-0145 }\end{array}$ \\
\hline
\end{tabular}

\section{Phase transformation of $\mathrm{Ni}_{50} \mathbf{T i}_{50}$ alloy}

Fig. 3 depicts the DSC curves of the $\mathrm{Ni}_{50} \mathrm{Ti}_{50}$ alloy. Each DSC curve of $\mathrm{Ni}_{50} \mathrm{Ti}_{50}$ shows only one peak during the heating and cooling process, which indicates a one-step B2 $\leftrightarrow$ B19' phase transformation. The effect of Ni-Ti concentration on martensitic transformation start temperature $M_{s}$. For Ni-Ti alloy, the $M_{s}$ is measured to be $77.44{ }^{\circ} \mathrm{C}$. It is well known that quenched Ni-Ti binary alloys show one-step B2 $\leftrightarrow$ B19' transformation and the transformation temperatures are strongly dependent on $\mathrm{Ni}$ concentration. 0.1 at. \% increase in $\mathrm{Ni}$ concentration can lower the $M_{s}$ of Ni-Ti binary alloys by more than $10{ }^{\circ} \mathrm{C}$. For example, Liu et al measured the $M_{s}$ to be about $-50{ }^{\circ} \mathrm{C}$ for $\mathrm{Ni}_{50.7} \mathrm{Ti}_{49.3}$ alloy after annealing at
$900{ }^{\circ} \mathrm{C}$ for $60 \mathrm{~min}$. T.A.Tabish et al measured the $M_{s}$ to be $-22.12{ }^{\circ} \mathrm{C}$ for $\mathrm{Ni}_{50} \mathrm{Ti}_{50}$ alloy after annealing at $1000{ }^{\circ} \mathrm{C}$ for $120 \mathrm{~min}$ [8]. R.J.Wasilewski et al measured the $M_{s}$ to be $65^{\circ} \mathrm{C}$ for $\mathrm{Ni}_{49.8} \mathrm{Ti}_{50.2}$ alloy [9]. In this work, the composition of the matrix is measured to be $\mathrm{Ni}_{49.36} \mathrm{Ti}_{50.64}$, which is Ti-rich. So, a high $M_{s}$ of Ti-Ni binary alloy is reasonable. Again, the martensite transformations finish temperature $M_{f}$ in Ni-Ti alloy is higher than room temperature of 20 ${ }^{\circ} \mathrm{C}$. Thus, the martensite transformations have finished at room temperature and the Ni-Ti alloy should be in total martensite phase, which is in agreement with the XRD results.

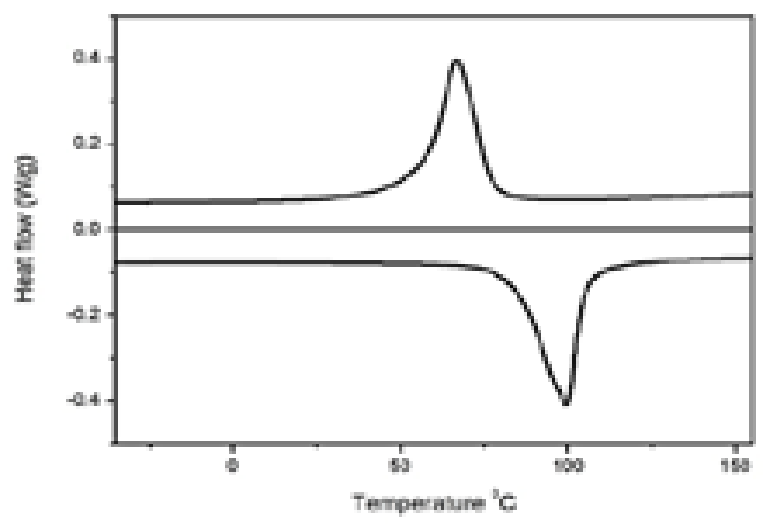

Figure. 3 DSC curve of $\mathrm{Ni}_{50} \mathrm{Ti}_{50}$

\section{CONCLUSIONS}

In summary, the microstructure and phase transformation behavior was investigated by XRD, SEM and DSC. The microstructure of the $\mathrm{Ni}_{50} \mathrm{Ti}_{50}$ alloys consists of $\mathrm{NiTi}_{2}$ alloy and NiTi matrix. The

\section{REFERENCES}

[1] K. Otsuka, and X. Ren, "Recent developments in the research of shape memory alloys," Intermetallics, vol. 7, no. 5, pp. 511-528, 1999.

[2] J. Frenzel, J. Pfetzing, K. Neuking, et al, "On the lattice parameters of NiTi matrix is a $=0.2898 \mathrm{~nm}$, $\mathrm{b}=0.4121 \mathrm{~nm}, \mathrm{c}=0.4619 \mathrm{~nm}$. The Ni-Ti alloy has a one-step martensitic transformation.

influence of thermomechanical treatments on the microstructure and phase transformation behavior of Ni-Ti-Fe shape memory alloys," Mat. Sci. Eng. A, vol. 482-484, pp. 635-638, 
2008.

[3] X.L. Meng, W. Cai, Y.D Fu, et al, "Shape memory behaviors in an aged Ni-rich TiNiHf high temperature shape-memory alloy," Intermetallics, vol. 16, no. 5, pp. 698-705, 2008.

[4] Y. Liu, M. Kohl, K. Okutsu, et al, "TiNiPd thin film microvalve for high temperature applications," Mat. Sci. Eng. A, vol. 378, no. 12, pp. 205-209, 2004.

[5] K. Otsuka, X. Ren, "Physical metallurgy of TiNi-based shape memory alloys," Prog. Mater. Sci., vol. 50, no. 5, pp.511-678, 2005.

[6] W. Cai, A.L. Liu, J.H. Sui, L.C. Zhao, "Effects of Cerium Addition on Martensitic Transformation and Microstructure of $\mathrm{Ti}_{49.3} \mathrm{Ni}_{50.7}$
Alloy," Mater. Trans., vol.47, no. 3, pp. 716-719, 2006.

[7] J.W. Xu, A.L. Liu, W. Cai, "Crystal structure and formation mechanism of rare earth rich phases in Ti-Ni-Ce alloys," J. Funct. Mater., vol.39, no.4, pp. 600-602, 2008.(in Chinese)

[8] T.A. Tabish, S. Atiq, M. Ali, A.N. Ch, Z.U. Reham, T.Z. Butt, "Development and characterization of $\mathrm{Ni}_{50} \mathrm{Ti}_{50}$ shape memory alloy used for biomedical applications," Int. J. Chem Mater. Sci. Eng., vol. 7, no. 12, pp. 92-93, 2013.

[9] R.J. Wasilewski, S.R. Butler, J.E. Hanlon, “On the Martensitic Transformation in TiNi," Met. Sci. J., vol. 1, pp. 104-110, 1967. 